\title{
La SUSTENTABILIdAd FINANCIERA DE PEMEX EN EL MARCO DE LA REFORMA ENERGÉTICA
}

\section{Dr. Raúl Cornejo López ${ }^{1}$}

\section{Mtro. Marcial Reyes Tépach ${ }^{2}$}

\section{Dra. Nadima Simón Domínguez ${ }^{3}$}

\section{Resumen}

Este trabajo tiene como objetivo analizar la sustentabilidad financiera de PEMEX en el marco del nuevo modelo de competencia de tipo endo-privatizador, emergido de la reforma energética en materia de hidrocarburos. En el estudio se definen la exo y endo-privatización, se destacan las características de PEMEX como empresa productiva del Estado, adicionalmente, se examina la fragilidad de su sustentabilidad financiera, su régimen fiscal y los instrumentos financieros que la reforma energética le proporcionó para que compita en el actual ambiente de apertura generalizada.

Palabras claves: PEMEX, endo-privatización, sustentabilidad, hidrocarburos

\section{Abstract}

This paper analyzes the financial sustainability of PEMEX within the new model of endo-privatization competition, emerging from the ener-

1 Profesor-investigador en la Universidad Autónoma Metropolitana Unidad Iztapalapa desde 1986 y profesor en la maestría en Finanzas en la Facultad de Contaduría y Administración de la UNAM.

2 Investigador de la Cámara de Diputados del Congreso de la Unión y doctorante en el programa de Ciencias de la Administración en la Faculta de Contaduría y Administración de la UNAM.

3 Profesora-investigadora emérita en la Facultad de Contaduría y Administración de UNAM, donde ha sido catedrática por 40 años.

Los juicos de valor son responsabilidad de los autores y no representan el punto de vista de las instituciones donde laboran. 
gy reform in the field of hydrocarbons. The study defines the exo and endo-privatization, highlights the characteristics of PEMEX as a state productive enterprise, additionally, examines the fragility of its financial sustainability, its fiscal regime and the financial instruments that the energy reform provided for it to compete in the generalized open environment.

Keyword: PEMEX, endo-privatization, sustainability, hydrocarbons

\section{Introducción.}

El modelo de competencia de la industria de los hidrocarburos del país era intervencionista, fue impulsado por el Gobierno Federal a través de Petróleos Mexicanos (PEMEX) que, de jure, era el único organismo descentralizado de la Administración Pública Federal, responsable de desarrollar y explotar todas las cadenas de valor económico de esta actividad, inhibiendo la concurrencia de los particulares.

Este modelo nacionalista se reformó en los años 2013 y 2014, para dar paso a otro de tipo endo-privatizador en materia de hidrocarburos (petróleo y gas natural), que desreguló las restricciones normativas, y así concurran nuevos jugadores, como las empresas productivas del Estado y los particulares, a través del régimen de asignaciones, contratos, permisos y autorizaciones.

Para que PEMEX compita en este nuevo modelo endo-privatizador, se reformó su naturaleza jurídica, dejando de ser un organismo descentralizado de la Administración Pública Federal, de carácter monopólico, responsable de desarrollar todas las cadenas de valor de la industria petrolera del país, transformándose en una "empresa productiva del Estado", propiedad del Gobierno Federal. De acuerdo con el texto vigente del artículo 27 Constitucional, su objeto es generar valor económico y rentabilidad para el Estado Mexicano. PEMEX, como empresa productiva del Estado, dejó de ser una subsidiaria del desarrollo sectorial del país, proveyendo energéticos a precios inferiores a los costos de producción para priorizar el principio de maximización de la utilidad. Es 
decir, se rige con los criterios rectores de una empresa mercantil, dentro de la esfera del sector público.

El objetivo general de este estudio es analizar la sustentabilidad financiera de PEMEX en el marco del nuevo modelo de competencia de tipo endo-privatizador, emergido de la reforma energética en materia de hidrocarburos, aprobada en México en el periodo 2013-2014.

El problema de investigación surge por el contexto en que se reformó la industria de los hidrocarburos y se cambió la naturaleza jurídica de PEMEX, el cual se llevó a cabo en un periodo de contracción de los ingresos de esta empresa, debido a la caída de los precios internacionales del petróleo y en un marco de una histórica fragilidad financiera motivada particularmente por su endémica carga fiscal, lo que abre interrogantes sobre su capacidad para competir en este ambiente de apertura generalizada de esta trascendental actividad económica nacional.

La hipótesis general de trabajo se centra en torno a su régimen fiscal, que es el problema financiero que históricamente ha impedido el desarrollo autónomo de esta empresa, se enuncia en los siguientes términos: Si el nuevo modelo endo-privatizador de la industria nacional de los hidrocarburos contiene los instrumentos para reducir la carga fiscal de PEMEX, entonces se fortalecerá su endémica sustentabilidad financiera, prevaleciente ex ante a la aprobación de la reforma energética.

Para alcanzar el objetivo general planteado en esta investigación, se proponen cinco apartados. En el primero, se desarrolla una tipología de las privatizaciones: la exo-privatización entendida como un proceso donde el sector público transfirió activos productivos a los particulares, impactando a los sectores prioritarios de la economía nacional; la endo-privatización, no transfiere activos productivos del Estado, aunque desregula las restricciones que impiden que la inversión de los particulares penetre en las áreas estratégicas de la economía nacional, incluyendo la industria de los hidrocarburos, antes reservada de manera exclusiva al Estado mexicano. 
En el segundo, se definen algunos rasgos característicos de PEMEX, como empresa productiva del Estado, destacando que opera con criterios de maximización de la utilidad, propio de una empresa mercantil, aunque dentro de la esfera del sector público. Esta transformación pretende facilitar la inserción de nuestra empresa petrolera en el nuevo ambiente de competencia.

En el tercero, se analiza la sustentabilidad financiera de PEMEX, explicada coyunturalmente por el fin del auge petrolero, y estructuralmente por un círculo vicioso que retroalimenta la alta carga fiscal que soporta esta empresa. Lo que conlleva a bajos niveles de flujos de inversión productiva $\mathrm{y}$, como consecuencia, incrementa la contratación de endeudamiento. En estas condiciones se llevó a cabo el proceso de apertura de la industria nacional de los hidrocarburos, sometiendo a nuestra empresa petrolera a una férrea competencia con empresas petroleras que, contrario a ésta, gozan de finanzas sólidas.

En el cuarto, se expone comparativamente el régimen fiscal de PEMEX abrogado y el vigente, con el objeto de identificar si la reforma energética aprobó mecanismos para la reducción de su carga fiscal que le permita sanear su endeble sustentabilidad financiera. El análisis se centra en su régimen de derechos y en el dividendo estatal.

En el quinto, se cuestionan los instrumentos financieros que la reforma energética le proporcionó a PEMEX para que compita en este ambiente de apertura generalizada, destacando por su importancia las asignaciones y las migraciones, estas últimas altamente flexibles, facultando a nuestra empresa petrolera asociarse con los particulares y de esta manera alcanzar la sustentabilidad financiera.

\section{Tipología de privatizaciones}

El proceso de privatización en nuestro país ha transitado por dos etapas: la primera, se denomina exo-privatización, su característica central fue que el sector público transfirió activos productivos hacia los particulares, permitiéndoles penetrar en los sectores prioritarios de la economía nacional, moviendo al Estado hacia fuera del mercado; la segunda, 
denominada endo-privatización, donde el sector público mantiene la propiedad de sus activos, aunque desregula las restricciones jurídicas para que los particulares inviertan ilimitadamente en diversas áreas de la economía nacional, incluyendo las estratégicas, en este proceso, el mercado se mueve hacia dentro del Estado.

A partir de la implementación del nuevo modelo económico-administrativo en 1982, se distinguen dos olas privatizadoras; en la primera, se puso énfasis en la necesidad de un "menor" Estado, por lo cual se realizó la exo-privatización de los activos y servicios ofrecidos desde la esfera pública para, posteriormente, iniciar la disertación sobre el "mejor" Estado, apoyándose en los principios de la endo-privatización (Vicher, 2009:141). Desde este enfoque, el objetivo de la exo-privatización fue reducir el tamaño del Estado, promoviendo agresivamente su contracción, bajo el supuesto de que cualquier acción podría ser ejecutada más eficientemente por el sector privado. Para Guerrero (2003:385386) consiste en el procedimiento por el cual la administración pública transfiere la producción de bienes y servicios a la administración privada. Pasaron más de dos décadas después de agotarse esta etapa para iniciar la endo-privatización, definida por este autor como "La sustitución de la administración pública de los asuntos nacionales, por la idea, la metodología y la técnica de la gerencia privada, moviendo al mercado hacia dentro del Estado."

Stricto sensu, la reforma energética en materia de hidrocarburos no la podemos calificar de exo-privatizadora. Para S. Bach, citado por Vicher, privatizar "es un término con el que se ha hecho referencia a la transferencia de activos del sector público al privado, ya sea [...] de pro $\neg$ piedad, de gestión, de finanzas o control”. Paul Starr, también citado por Vicher, entiende este concepto como "un cambio de lo público a lo privado en la producción de [bienes] y servicios", distinguiendo cuatro tipos de política gu $\neg$ bernamental que derivan en privatización, una de ellas es la transferencia de activos públicos a la propiedad privada (tierra, infraestructura y empresas) (Vicher, op. cit.: 144).

La reforma al sector de los hidrocarburos tuvo como centro de su propuesta endo-privatizar, porque el Estado mexicano mantuvo bajo su 
propiedad y dominio los hidrocarburos, que son activos del subsuelo, propiedad de la Nación, y PEMEX como la empresa nacional responsable de explotar todas las cadenas de valor de esta industria.

Adicionalmente, la reforma energética desreguló las restricciones jurídicas a favor de la participación indiscriminada de los particulares en todos los segmentos de la industria nacional de los hidrocarburos, incluyendo los segmentos de la exploración y extracción. Las cuales quedaron reservados de manera exclusiva para el Estado, aunque no limitó la participación de los particulares, pudiendo hacerlo a través del régimen de contratos.

Este es el sentido de la endo-privatización: no reducir los activos del Estado, que quedan bajo su propiedad y dominio facilitando el arribo de los particulares en las actividades económicas del sector público, de esta manera, la inversión pública y privada no se conciben como excluyentes, sino concurrentes, compartiendo riesgos y beneficios.

El proceso endo-privatizador encierra una potencial trampa; consiste en la retirada gradual de la inversión estatal para que sean los particulares los que impulsen mayoritariamente el proceso productivo en las áreas donde participan, consumándose una privatización sui géneris, porque la propiedad y dominio de los activos se mantienen en la esfera del sector público, aunque la inversión y la mayor proporción de las utilidades se realice y transfiera a los inversionistas privados.

Con la coparticipación de la inversión pública y la privada en las actividades económicas del sector público, se abrogan los procesos monopólicos estatales, desarrollando un proceso de competencia dentro de la esfera gubernamental, migrando hacia esquemas productivos regidos por el principio de la eficiencia económica, que es el que guía a los mercados.

Veamos el proceso de endo-privatización de la industria nacional de los hidrocarburos por segmentos:

a. Las actividades estratégicas de exploración y extracción de petróleo y gas: su respectiva explotación se reservó de manera ex- 
clusiva para el Estado mexicano, permitiéndose la concurrencia de la inversión pública a través de las empresas productivas del Estado vía asignaciones, con la de los particulares (personas morales de cualquier nacionalidad) que celebran contratos con el Gobierno Federal.

b. La perforación de pozos exploratorios; pozos en aguas profundas y ultra-profundas y pozos tipo que se utilicen como modelos de diseño, se otorgan autorizaciones a los asignatarios y contratistas.

c. Los demás segmentos de hidrocarburos se definen como "actividades y servicios de utilidad pública”, están amparadas por un permiso que se otorga a favor de cualquier empresa productiva del Estado y a los particulares. Bajo esta modalidad concurren el tratamiento y refinación de petróleo; el procesamiento de gas natural; la exportación e importación de hidrocarburos y petrolíferos; el transporte, almacenamiento, distribución, compresión, licuefacción, descompresión, regasificación, comercialización y expendio al público de hidrocarburos, petrolíferos o petroquímicos y la gestión de los sistemas integrados.

d. Para realizar actividades de comercialización de hidrocarburos, petrolíferos y petroquímicos en territorio nacional se requiere de permisos, que se otorgan a las empresas productivas del Estado y a los particulares.

\section{Nueva naturaleza jurídica de PEMEX}

Con este modelo de competencia endo-privatizador, la naturaleza jurídica de PEMEX también se reformó, dejó de ser un organismo descentralizado de la Administración Pública Federal, de carácter monopólico, responsable de desarrollar toda la industria de los hidrocarburos del país, para "transformarse" en una "empresa productiva del Estado".

En su Ley Reglamentaria, PEMEX es una empresa productiva del Estado de propiedad exclusiva del Gobierno Federal: con autonomía técnica, operativa y de gestión, con personalidad jurídica y patrimonio propios, constituido por los bienes, derechos y obligaciones que haya 
adquirido y se le hayan asignado, transferido o adjudicado. Así como por los rendimientos e ingresos que deriven de sus operaciones o cualquier otro concepto.

PEMEX nos proporciona la siguiente definición de sí misma:

[...] es una persona moral de derecho público controlada por el Gobierno Federal, misma que es parte de la Administración Pública Federal sin considerarse una entidad paraestatal, con personalidad jurídica y patrimonio propios, con autonomía técnica, operativa y de gestión en los términos que determine su ley, cuyo objeto es desarrollar la actividad estratégica del Estado consistente en la exploración y extracción del petróleo y de los carburos de hidrógeno sólidos, líquidos o gaseosos, así como su recolección, venta, transformación y comercialización, incluyendo su transformación, venta y comercialización de sus derivados, mediante el desarrollo de actividades empresariales, económicas, industriales y comerciales en términos de su objeto, generando valor económico y rentabilidad para el Estado Mexicano como su propietario, con sentido de equidad y responsabilidad social y ambiental (PEMEX, 2015:10).

Nadie objetará que las empresas productivas del Estado, incluyendo a PEMEX, son entes públicos y no privados porque tienen su origen en normas de derecho público; llevan a cabo una actividad estratégica reservada exclusivamente al sector público y son propiedad exclusiva del Gobierno Federal. Asimismo, el control que el Gobierno Federal, en su carácter de propietario, lleva a cabo a partir de la intervención de los Titulares de la Secretaría de Energía (SENER) y la Secretaría de Hacienda y Crédito Público (SHCP), igualmente la facultad del Ejecutivo Federal para designar a los miembros de sus Consejos de Administración (Cossío, 2015:16).

El cambio de la naturaleza jurídica de PEMEX es ad hoc al nuevo modelo endo-privatizador, para competir por asignaciones y contratos con los particulares, debe modificar su mística, guiándose por los principios 
de la eficiencia económica, propia de los mercados, aunque dentro de la esfera gubernamental.

\section{Sustentabilidad financiera de PEMEX}

Sin embargo, a PEMEX se le sometió a un proceso de competencia en un ambiente adverso, que se distingue por dos procesos, uno coyuntural y otro estructural, que han afectado significativamente la sustentabilidad de sus finanzas:

a. El coyuntural, está relacionado con el fin de un periodo de bonanza definido como auge petrolero, que favoreció a los países productores y exportadores de hidrocarburos. Su rasgo principal fue el incremento de los precios promedios de la mezcla mexicana de petróleo de exportación, el cual pasó de 10.18 dólares por barril (DPB) en 1998, hasta alcanzar su máximo histórico de 101.96 DPB en el 2012. Durante el periodo 2013 al 2015, estos precios iniciaron una etapa de declinación de 94.44 DPB, 85.48 DPB y 43.29 DPB en promedio anual, respectivamente.

El incremento de los precios impactó favorablemente el valor de las exportaciones del crudo mexicano. Específicamente, en 1998 la ventas eran de 6 mil 448 millones de dólares (MMDD); en el 2011 alcanzaron su nivel más alto, fueron de 49 mil 380 MMDD; en el 2012 fueron de 46 mil 852 MMDD. Entre el 2013, 2014 y 2015, el valor de las exportaciones se redujo sensiblemente a 42 mil 711 MMDD, 35 mil 638 MMDD y 18 mil 524 MMDD respectivamente, asociándose directamente con la crisis internacional de los precios de los hidrocarburos. El auge petrolero llegó a su fin en el 2013, cuando los precios de la mezcla mexicana de petróleo de exportación se cotizaron por debajo de los 100 DPB, iniciándose un periodo de caídas generalizadas de los precios internacionales del petróleo, reduciéndose el valor de las exportaciones de esta materia prima.

b. El estructural, está relacionado con la falta de sustentabilidad de las finanzas de PEMEX, producto de su pesada carga fiscal que re- 
troalimenta un círculo perverso, puesto que, las obligaciones que históricamente ha tenido en materia de financiamiento del gasto público del Gobierno Federal, ha reducido su capacidad de inversión, obligándola a apalancarse con crecientes flujos de endeudamiento y su natural impacto en el incremento de su servicio.

Este círculo perverso presenta los siguientes rasgos:

i. La carga que soporta PEMEX sistemáticamente ha sido superior a sus rendimientos antes de la aplicación del régimen fiscal. En el 2000, sus utilidades previas de estas obligaciones eran de 274 mil 057 MMDP, los impuestos y derechos petroleros que pagó fueron de 293 mil 768 MMDP. Esta tendencia se mantuvo en todo el periodo, objeto de estudio, con excepción de los años 2006 y 2012.

En el 2014, las ganancias antes de la aplicación del régimen fiscal fueron de 480 mil 530 MMDP, en tanto la carga fiscal que soportó fue de 746 mil 075 MMDP. El grado de extracción fiscal hacia esta empresa petrolera fue sui géneris en el 2015, en ese año PEMEX registró pérdidas en sus rendimientos antes de impuestos, y sobre números rojos pagó sus obligaciones al Gobierno Federal. Esto la llevó a cerrar el año fiscal con una pérdida de 712 mil 570 MMDP, es decir, sobre sus utilidades negativas pagó su carga fiscal al Gobierno Federal, particularmente los derechos por exploración y extracción de hidrocarburos.

Otra manera de analizar el nivel de extracción de las utilidades de PEMEX por parte del Gobierno Federal es a través de un indicador financiero que relaciona la carga fiscal sobre los rendimientos, antes de la aplicación del régimen impositivo. Para el periodo 20002015 , este indicador es mayor que 1 , con excepción de los años 2006 y 2012, lo que significa que las obligaciones impositivas de esta empresa petrolera fueron superiores a sus utilidades. Específicamente, en el año 2000 la carga fiscal fue $7.19 \%$ superior que las utilidades antes de la aplicación del régimen fiscal, en el 2014 fue superior a $55.26 \%$. 
ii. La pesada carga fiscal que PEMEX soporta reduce su capacidad de inversión, las cuales pasaron de 71 mil 725 millones de pesos (MMDP) en el 2000 a 366 mil 352 MMDP en el 2015. Desde 1995, la estrategia gubernamental consistió en fortalecer la inversión privada en este sector, por tal razón, hasta el 2008 la inversión productiva de esta empresa provenía de dos fuentes:

La primera, eran los esquemas Proyectos de Infraestructura Productiva con Impacto Diferido en el Registro del Gasto (PIDIREGAS), los cuales pasaron de 42 mil 888 MMDP en el 2000 a 177 mil 967 MMDP en el 2008, cuando se abrogaron. La segunda era la inversión pública, que redujo su participación mientras se permitía la inversión privada, su participación pasó de 28 mil 837 MMDP a 23 mil 773 MMDP. Los esquemas PIDIREGAS para PEMEX se abrogaron a partir del 2009. Desde entonces, toda la inversión productiva de esta empresa es de origen gubernamental.

Para identificar la insuficiencia de la inversión productiva de PEMEX, se correlacionó con el nivel de producción de hidrocarburos líquidos y petrolíferos. La inversión productiva en PEMEX, aunque fue ascendente, resultó insuficiente porque no pudo contener la caída de la producción de hidrocarburos ni del crudo. El coeficiente de correlación nos muestra una relación inversa entre estas variables, su estimación fue de -0.912 y de -0.9059 , respectivamente, lo que implica que a medida que se incrementa la inversión productiva, la producción de hidrocarburos y de petrolíferos se reduce.

iii. Como consecuencia de este modelo financiero reservado para PEMEX, su flujo anual de endeudamiento se incrementó significativamente, pasando de 325 mil 426 MMDP en el 2002 a 1 billón 493 mil 385 MMDP en el 2015.

El financiamiento de PEMEX está relacionado con sus rendimientos netos después de la aplicación de su régimen fiscal. El coeficiente de correlación fue de -0.8367 , lo que significa que ambas variables se relacionan en sentido inverso, es decir, en la medida que se reducen las utilidades netas de PEMEX, se incrementa 
el flujo de endeudamiento. Particularmente, en los años 2014 y 2015, las pérdidas netas de esta empresa petrolera aumentaron de manera sin precedente en 265 mil 545 MMDP y 712 mil 570 MMDP, respectivamente, como consecuencia, para compensar estos flujos de ingresos, se contrataron nuevos endeudamientos, los cuales ascendieron a 302 mil 010 MMDP y de 350 mil 135 MMDP, respectivamente.

\section{Reforma al régimen fiscal de PEMEX}

PEMEX tiene múltiples problemas financieros, podemos citar los relacionados con los excesos de su dirigencia sindical y de su alta gerencia, provocados por la opacidad y desinterés para rendir cuentas. Estas prácticas impactan sus finanzas, aunque el más significativo tiene carácter estructural, está relacionado con su régimen fiscal, es la fuente principal de retroalimentación de su círculo vicioso relacionado con la sobrecarga fiscal, baja inversión y alto endeudamiento.

La reforma energética modificó el régimen fiscal de PEMEX. De acuerdo con la Ley de Ingresos sobre Hidrocarburos, actualmente soporta tres derechos: por la Utilidad Compartida, de Exploración de Hidrocarburos y de Extracción de Hidrocarburos. El número de derechos son menores a los existentes antes de la reforma, los cuales eran nueve: Ordinario sobre Hidrocarburos; para la Investigación Científica y Tecnológica en Materia de Energía; para la Fiscalización Petrolera; para Regular y Supervisar la Exploración y Extracción de Hidrocarburos; sobre Hidrocarburos para el Fondo de Estabilización; Extraordinario sobre la Exportación de Petróleo Crudo; además de tres derechos por la extracción de petróleo crudo y gas natural en los campos del Paleocanal de Chicontepec, de Aguas Profundas y Campos Marginales. (Ver tabla número 1).

Desde la perspectiva comparada, dado el menor número de derechos que conforman el nuevo régimen, pareciera que la carga fiscal que PEMEX paga al Gobierno Federal se ha reducido. Sin embargo, los antecedentes de este régimen evidencian un rasgo sui géneris: su principal 
obligación es producto de un derecho que afecta significativamente sus ingresos, al impactar el valor de las ventas. Antes de la reforma, era el "Derecho Ordinario Sobre Hidrocarburos" que aplicaba una tasa del $71.5 \%$ sobre la diferencia que resultaba entre el valor anual del petróleo crudo y gas natural extraídos en el año y las deducciones permitidas. Con la reforma, éste se modificó por el "Derecho de Utilidad Compartida" que aplica una tasa del 65\% a la diferencia que resulte de disminuir del valor de los hidrocarburos extraídos y las deducciones permitidas. El resto de los derechos tienen impactos marginales en las finanzas de esta empresa petrolera. 


\begin{tabular}{|c|c|c|c|c|c|c|c|}
\hline 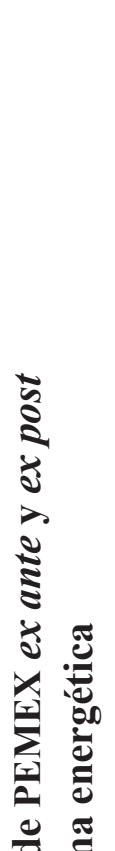 & 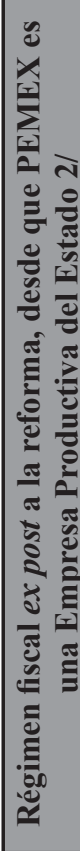 & 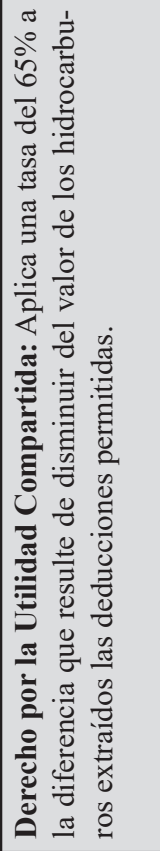 & & & 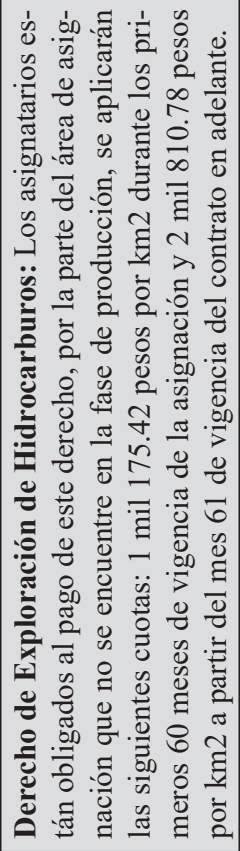 & & \\
\hline 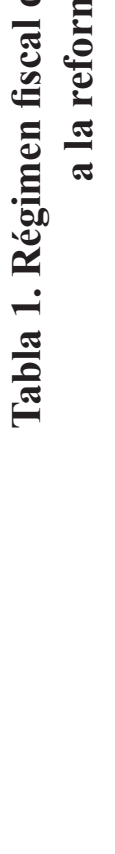 & 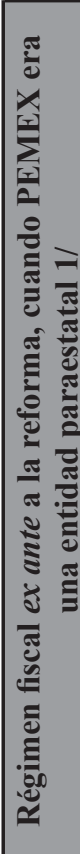 & 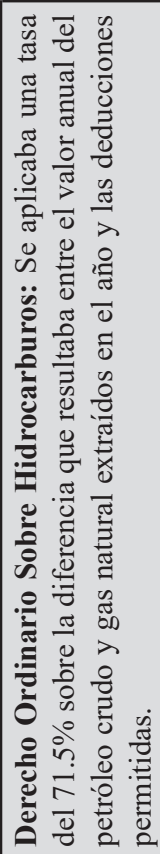 & 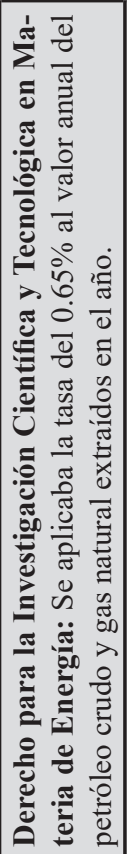 & 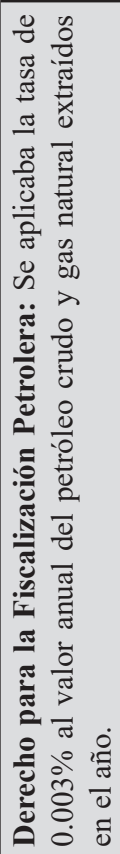 & 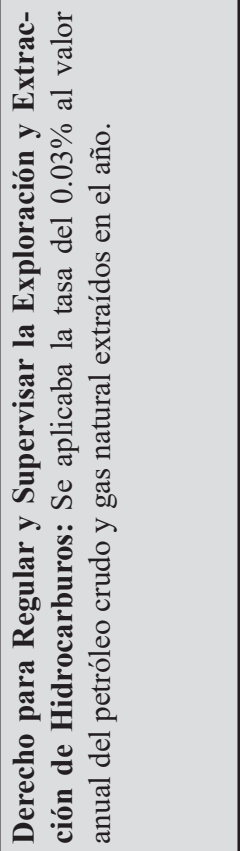 & 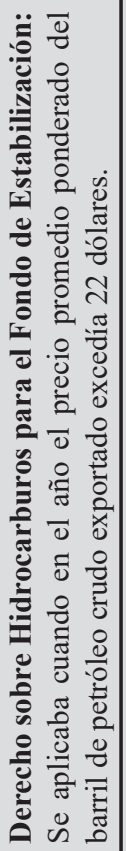 & 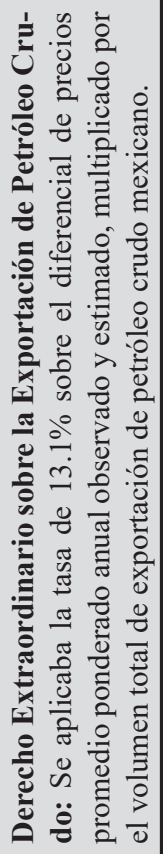 \\
\hline
\end{tabular}




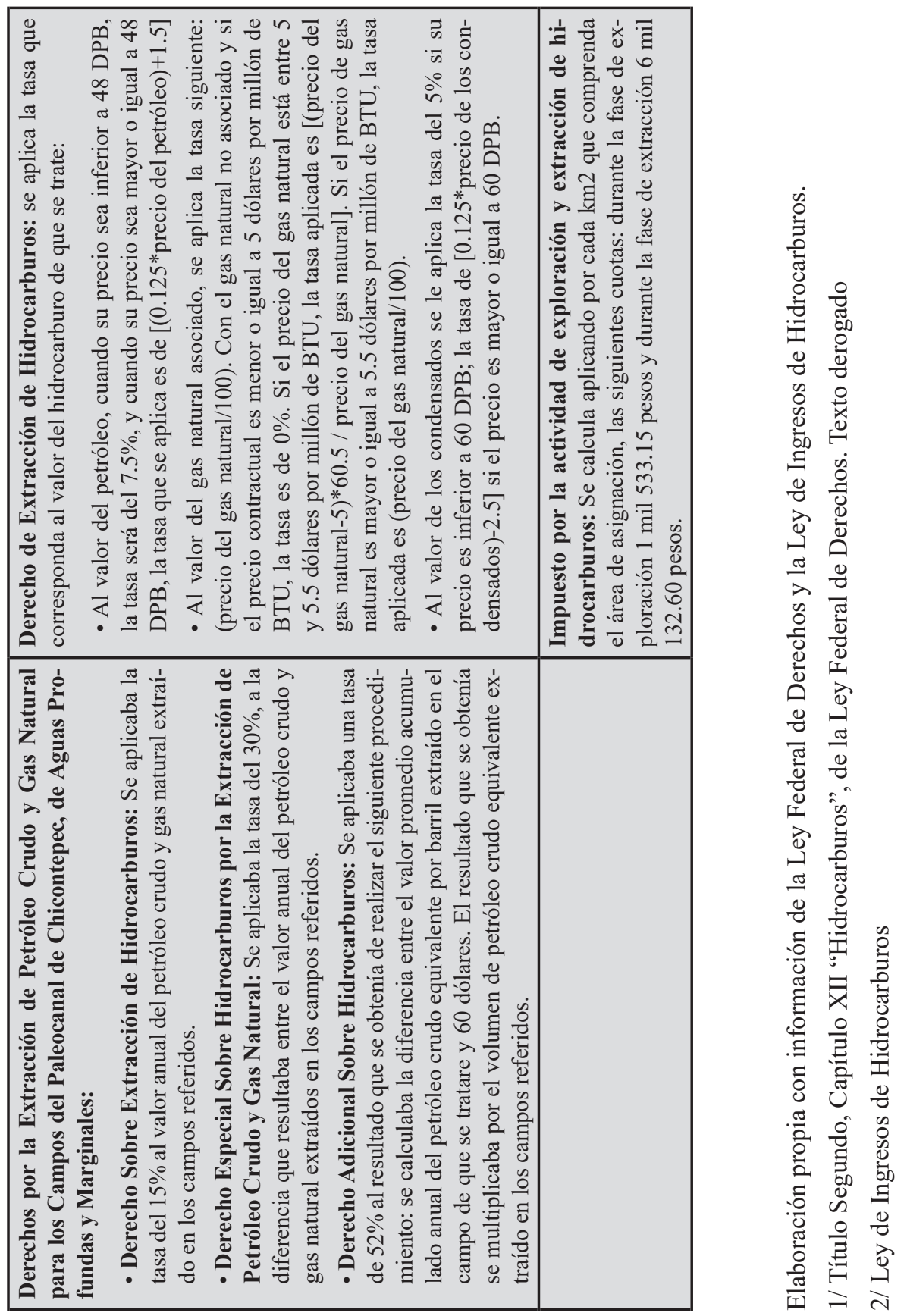


Ambos derechos mantienen la naturaleza extractiva de los ingresos generados por PEMEX después de aplicar las deducciones permitidas. Las tasas pasaron del 71.5 a 65\%, el ahorro que esta Empresa Productiva del Estado obtuvo con el nuevo régimen es del 6.5\% del valor de sus ventas, respecto a la tasa que aplicaba el Derecho Ordinario sobre Hidrocarburos.

Llama la atención que el derecho vigente se llama de "Utilidad Compartida", que presupone que las ganancias de PEMEX se distribuyen entre esta empresa y el Gobierno Federal, aunque en una proporción desequilibrada porque éste último se apropia del 65\% de las utilidades y le deja a la petrolera el 35\% para que enfrente su compleja situación financiera. Compartir utilidades con criterios de equidad implicaría una relación de al menos $50 \%$ a cada actor.

Adicionalmente al régimen de derechos, en los artículos 97, 98, 99 y Décimo Cuarto Transitorio de la Ley de Petróleos Mexicanos se regula el dividendo estatal, que obliga a PEMEX y a sus empresas productivas subsidiarias entregar anualmente al Gobierno Federal parte de sus utilidades después de aplicar el régimen fiscal.

La lógica del dividendo estatal está en función de la naturaleza jurídica de PEMEX, que es una empresa moral de propiedad estatal, por lo tanto, si genera utilidades después de impuestos, debe asignar una parte a sus accionistas, en este caso al Gobierno Federal, el Consejo de Administración define el destino de los remanentes de sus ganancias.

De acuerdo con el artículo Décimo Cuarto Transitorio de la Ley de Petróleos Mexicanos, el dividendo estatal entró en vigor en el año 2015, para el ejercicio fiscal 2016 es, como mínimo, equivalente al 30\% de los ingresos después de impuestos que generen PEMEX y sus empresas productivas subsidiarias durante el 2015, reduciéndose para los siguientes ejercicios hasta alcanzar un 15\% en el 2021 y $0 \%$ en el 2026.

[...] Al ser un monto impuesto por el Gobierno Federal, la figura del dividendo estatal tiene más similitudes con las de una contribución, específicamente con la de un derecho. En este senti- 
do, parece que el dividendo estatal es un derecho disfrazado. El problema que presenta esta simulación es que los derechos deben cumplir con las garantías constitucionales en materia fiscal (proporcionalidad, equidad, destino a gasto público y legalidad); mientras que, si no se considera al dividendo estatal como una contribución, entonces no deberá cumplir con dichas garantías.

Por lo tanto, la SHCP no tiene un límite en cuanto a la determinación del monto que PEMEX deberá entregar, pudiendo establecer que como dividendo estatal se pague la totalidad de las utilidades de la empresa. Si se pretende que PEMEX pueda competir con otras empresas dentro del sector hidrocarburos, resulta conveniente que ésta determine los montos que reinvertirá en sí misma; sin embargo, esto sólo podrá hacerse con el remanente de las utilidades una vez pagado el dividendo estatal (PEMEX, op. cit.: 47-48).

De esta manera, PEMEX por explotar un recurso natural del subsuelo propiedad de la Nación, está obligado a soportar un régimen fiscal extractivo de sus utilidades, puesto que adicionalmente a su carga de impuestos, contribuye con diversos derechos petroleros y con el dividendo estatal, que transforman sus utilidades en pérdidas. Su situación financiera pasa de números negros a rojos.

Ninguna empresa moral puede subsistir con un esquema tan extractivo como el que ha enfrentado PEMEX por décadas. Su régimen fiscal es la principal fuente de recaudación de los ingresos petroleros del Gobierno Federal, paradójicamente este mecanismo extractivo ha tenido a esta empresa en una profunda crisis financiera, impidiéndole desarrollar su potencial productivo. Por un lado, es la principal fortaleza del Estado mexicano, por otro lado, el sistemático apropiamiento de sus utilidades le resta competitividad en este ambiente de apertura generalizada.

\section{Instrumentos reservados para que PEMEX compita en el nuevo modelo Endo-privatizador}

La reforma energética le reservó a PEMEX el régimen de asignaciones, como el instrumento más importante para que pueda competir con los 
particulares, personas morales, en los segmentos estratégicos de la industria nacional de los hidrocarburos (exploración y extracción).

Tradicionalmente, en el derecho administrativo mexicano se recurre a esta figura para que los organismos gubernamentales se incorporen a las áreas estratégicas y prioritarias a las que el Estado renuncia. Becerra, citado por Ramírez, estableció que la asignación es "el acto administrativo por el cual se incorpora al patrimonio de las entidades, los derechos para explotar sustancias en zonas determinadas" (2003:382).

Sánchez, sobre la asignación, afirma que: "Estamos en presencia de un acto jurídico de derecho público que expide la administración pública federal, a favor de organismos y dependencias públicas para explotar, disponer y aprovechar bienes del dominio directo de la Nación, por causas de orden público y de necesidad social [...]" (2002: 118-119).

En la Ley de Hidrocarburos, se establece que la explotación de las áreas estratégicas de esta industria se realiza a través de asignaciones y contratos. En lo relacionado con las primeras, esta Ley las define como "El acto jurídico administrativo mediante el cual el Ejecutivo Federal otorga exclusivamente a un asignatario el derecho para realizar actividades de exploración y extracción de hidrocarburos en el área de asignación, por una duración específica."

Los asignatarios son PEMEX o cualquier otra empresa productiva del Estado, que sea titular de una asignación y operador de un área de asignación. Esta última se define en la Ley de Hidrocarburos como "La superficie y profundidad determinadas por la Secretaría de Energía, así como las formaciones geológicas contenidas en la proyección vertical en dicha superficie para dicha profundidad, en las que se realiza la exploración y extracción de hidrocarburos a través de una asignación."

Adicionalmente, la Ley de Hidrocarburos reserva a PEMEX los siguientes instrumentos para que compita en este ambiente de apertura generalizada:

a. Migraciones: Donde PEMEX y las demás empresas productivas del Estado pueden solicitar a la SENER, con la asistencia técnica 
de la Comisión Nacional de Hidrocarburos (CNH), la migración de las asignaciones a contratos para la exploración y extracción de hidrocarburos, celebrando alianzas o asociaciones con personas morales.

b. Participación obligatoria del Estado mexicano: A través de PEMEX, de cualquier otra empresa productiva del Estado o de un vehículo financiero especializado del Estado Mexicano, cuando: el área contractual objeto de la licitación coexista, a distinta profundidad, con un área de asignación; existan oportunidades para impulsar la transferencia de conocimiento y tecnología para el desarrollo de las capacidades de PEMEX u otra empresa productiva del Estado, o se trate de proyectos que se deseen impulsar a través de un vehículo financiero especializado del Estado mexicano. En los dos primeros supuestos, la participación de PEMEX, de cualquier otra empresa productiva del Estado o del vehículo financiero especializado que se establezca en el contrato de exploración y extracción correspondiente, no podrá exceder del $30 \%$ de la inversión del proyecto.

c. Yacimientos transfronterizos: La SENER, con la asistencia técnica de la $\mathrm{CNH}$, establecerá una participación obligatoria de PEMEX u otra empresa productiva del Estado en los contratos para la exploración y extracción en aquellas áreas contractuales en las que exista la posibilidad de encontrar yacimientos transfronterizos. La participación obligatoria será de al menos $20 \%$ de la inversión del proyecto.

Como se puede observar, estos instrumentos son flexibles, que es un rasgo fundamental de este modelo endo-privatizador, porque le da la opción a PEMEX para desarrollar los proyectos de exploración y extracción con recursos presupuestales propios o formar alianzas o asociaciones con personas morales a través de las migraciones.

Los defensores de este modelo de competencia observan en estos esquemas la oportunidad para que PEMEX compita; otros observamos un riesgo que aumente su dependencia en estas modalidades de financiamiento, dando paso a un proceso de endo-privatización de esta empresa 
productiva del Estado, particularmente por su frágil sustentabilidad financiera, producto de su régimen fiscal extractivo.

\section{Conclusiones}

La reforma energética en materia de hidrocarburos implicó modificar diversos aspectos relacionados con la situación financiera de PEMEX. De manera particular, el régimen fiscal se hizo más simple. Ex ante a la reforma se conformaba de 9 derechos, ex post únicamente de 3 , aunque mantiene un derecho que es altamente extractivo de sus utilidades netas: el Derecho por la Utilidad Compartida considera una tasa del 65\%. Además de aplicar el dividendo estatal, concepto que se adicionó en la reciente reforma, lo que hace que su régimen fiscal sea tan extractivo como el existente en antaño.

De jure, PEMEX es una empresa productiva del Estado, que se debe regir con los principios de una empresa mercantil, priorizando la eficiencia económica, maximizando sus utilidades, aunque desenvolviéndose dentro de la esfera del sector público. De facto, con un régimen fiscal tan extractivo como el que se le aprobó en la reforma energética y con la frágil sustentabilidad financiera con la que opera, difícilmente podrá alcanzar los niveles de productividad de una empresa moral, el fin del auge petrolero exacerbó sus finanzas. Se ignoró un principio básico que debió seguirse: primero se tuvo que fortalecer la sustentabilidad financiera de esta empresa y después abrirla a la competencia.

Podemos concluir que el nuevo modelo endo-privatizador de la industria nacional de los hidrocarburos no contiene los instrumentos para reducir la carga fiscal de PEMEX, por el contrario, la exacerbó, como consecuencia, no fortalecerá su endémica sustentabilidad financiera, prevaleciente ex ante a la aprobación de la reforma energética.

Asimismo, para tener los rasgos de una empresa productiva que sea capaz de competir eficientemente en este ambiente de apertura generalizada, es necesario reducir su carga fiscal, dándole un tratamiento fiscal menos extractivo; al hacerla financieramente sustentable, y que pueda tener autonomía en sus proyectos productivos, reduciendo la dependen- 
cia en los mecanismos de migraciones aprobados, considerados por sus defensores como la solución para capitalizarla.

Las alianzas y asociaciones son instrumentos necesarios con el fin de que PEMEX compita e incremente la competitividad de sus factores productivos, sin embargo, la sustentabilidad de sus finanzas es una condición sine qua non para que se apodere de la mayor rentabilidad en los proyectos productivos que desarrolle con los particulares, de lo contrario, se corre el riesgo de que la renta petrolera sea transferida a los inversionistas privados, debilitando las finanzas del Gobierno Federal. Esta es la importancia estratégica de hacer financieramente autónoma a nuestra empresa petrolera.

El análisis financiero, nos permite concluir que nuestra empresa petrolera está compitiendo en este nuevo modelo endo-privatizador en condiciones de baja sustentabilidad financiera, con un régimen fiscal más extractivo que el existente ex ante a la reforma, con sobre endeudamiento e inversión propia insuficiente.

El primer paso para hacer a PEMEX financieramente sustentable es reducir su pesada carga fiscal, particularmente, la tasa del derecho de "Utilidad Compartida" debe fijarse considerando un criterio de mayor equidad. Actualmente el Gobierno Federal se apropia del 65\% de las utilidades de PEMEX y le deja a esta empresa el $35 \%$ para que enfrente su compleja situación financiera. Compartir utilidades con criterios de equidad implicaría una relación de al menos $50 \%$ a cada actor, aunque la tasa se debe reducir gradualmente para garantizar la productividad de nuestra empresa petrolera en este ambiente de alta competencia.

\section{Bibliografía}

Cossío, Barragán José Ramón, "Naturaleza jurídica de PEMEX como empresa productiva del Estado", Revista Legal y Económica, ITAM. Vol. 1, núm. 1, Ciudad de México, 2015, pp. 9-54.

Cámara de Diputados del Congreso de la Unión, Ley de Hidrocarburos Leyes Federales vigentes, Ciudad de México: http://www. 
diputados.gob.mx/LeyesBiblio/pdf/LHidro_110814.pdf [Consultado, 10 de marzo del 2017]

, Ley de Ingresos sobre Hidrocarburos. Leyes Federales Vigentes, Ciudad de México: http://www.diputados.gob.mx/LeyesBiblio/pdf/LIH_010416.pdf [Consultado, 12 de abril del 2017].

Cámara de Diputados del Congreso de la Unión, Ley de Petróleos Mexicanos. Leyes Federales Vigentes, Ciudad de México: http:// www.diputados.gob.mx/LeyesBiblio/pdf/LPM_110814.pdf [Consultado, 19 de marzo del 2017].

Guerrero, Omar, "Nueva Gerencia Pública: ¿Gobierno sin Política?", Revista Venezolana de Gerencia, Universidad de Zulia. Maracaibo, año/vol. 8, núm. 023, 2003, pp. 379-395.

PEMEX, Rol de PEMEX como empresa productiva del Estado, Ciudad de México: http://www.pued.unam.mx/archivos/seminario110515/ SE_M1M1_MAP.pdf [Consultado, 15 de abril del 2017].

, Anuario estadístico 2014: http://www.pemex.com/ri/Publicaciones/Anuario\%20Estadistico\%20Archivos/2014_ae_00_ vc_e.pdf [Consultado, 30 de marzo del 2017].

, Anuario estadístico 2005: http://www.pemex.com/ri/Publicaciones/Anuario\%20Estadistico\%20Archivos/2005_ae_00_ vc_e.pdf [Consultado, 25 de marzo del 2017].

, Estados financieros consolidados. Varios años: http:// www.pemex.com/ri/finanzas/Paginas/resultados.aspx [Consultado, 21 de abril del 2017].

Ramírez, Marín Juan, Derecho Administrativo Mexicano, Primer Curso, 1a edición, Porrúa e Instituto Tecnológico de Monterrey Campus Ciudad de México, México, 2009, pp. 507.

Sánchez, Gómez Narciso, Segundo Curso de Derecho Administrativo, 2a edición, Porrúa, México, 2002, pp. 530.

Vicher, Diana, De la reforma administrativa a la reforma neogerencial en Hispanoamérica, 1a edición, Instituto de Administración Pública del Estado de México, México, 2009, pp. 141-155. 